\title{
THE STRESS OF CARING: THE MANIFESTATION OF STRESS IN THE NURSE-PATIENT RELATIONSHIP
}

\author{
JC Schoombee, JM van der Merwe, L-M Kruger
}

\section{INTRODUCTION}

Following global trends in health reforms, South Africa has followed a primary health care approach since the eighties (Petersen \& Swartz, 2002; Van der Walt, 1998). The implementation of this approach at first was regarded as selective and piecemeal (Van der Walt, 1998), but with the emergence of a democratically elected government in 1994 a series of health reforms focused on equalising the coverage of service (Van Wyk, 2005). The South African health system can thus best be described as one that has been characterised by time-consuming restructuring processes aimed at the implementation of a comprehensive primary health care service. Within this system all health-care professionals have been exposed to stressful working conditions. However, mental health professionals (psychologists and social workers) agree that the impact of these conditions on nurses is specifically important as they form "...the largest cadre of frontline health providers in South Africa” (Van der Walt \& Swartz, 2002:1002).

Given their front-line status in a constantly changing health care system, it is not surprising that recent South African studies have repeatedly found nurses to suffer from extremely high levels of stress and burn-out (Cilliers, 2002; Levert, Lucas \& Ortlepp, 2000; Steenkamp \& Van der Merwe, 1998; Walker \& Gibson, 2004). Researchers have also focused on the consequences of such high levels of stress in nurses on the nurse-patient relationship (Altun, 2002; Bennett, Lowe, Matthews, Dourali \& Tattersall, 2001; Billeter-Koponen \& Fredén, 2005; Cox, 2001; Jewkes, Abrahams \& Mvo, 1998; Sand, 2003; Tselebis \& Moulou, 2001; Winstanley \& Richard, 2002) and ultimately on health care-seeking practices of South Africans (Abrahams, Jewkes, \& Mvo, 2001).

The current study of the psychological experiences of nurses in a maternity ward of a Western Cape state hospital formed part of a larger longitudinal study concerned with the emotional experiences of poor rural women during pregnancy, birth and the postpartum period (BurmeisterNel, 2005; Corbet-Owen \& Kruger, 2002; Grossman, Kruger \& Moore, 1999, 2000; Kruger, 2003; Kruger \& Van der Spuy, 2005; Lazarus \& Kruger, 2004, 2004a; Smit, 2002; Spies, 2001). Preliminary findings of the larger study strongly indicated that poor women who were participants in this study often experienced the nurse-patient relationship in the maternity ward as highly compromised - an experience that certainly impacted on their health-seeking practices (Kruger \& Van der Spuy, 2005). Given research on the impact of stress on nurses and the nurse-patient relationship, it seemed important from a mental health perspective to also focus on the emotional experiences of the maternity nurses themselves. It was assumed that such a focus would provide information which could be utilised by mental health workers (psychologists and social workers) in their efforts to provide appropriate support for these health-care workers - this would ultimately also be beneficial for patients. The team consequently decided to also conduct a study focused on the experiences of the nurses of the maternity ward of the local state hospital. In this paper the main findings of the first stage of the nurses' study are described: grounded theory was used to analyse in-depth interviews conducted with nurses. In the second part of the paper ('Violent nursing': A Foucauldian perspective on nursing in South Africa) the analytic categories that emerged during the first stage of the study will be discussed from a Foucauldian perspective. 


\section{RESEARCH METHODS}

\section{Theoretical points of departure}

The current two-part study was conducted chiefly from within the theoretical field of feminist poststructuralism. Weedon (in Gavey, 1989:460) described the intersection of feminism and poststructuralism as "...a mode of knowledge production which uses poststructuralist theories of language, subjectivity, social processes and institutions to understand existing power relations and to identify areas and strategies for change." On a more pragmatic level the theoretical orientation that guided this study was that of social constructionism, which falls within and is informed by the theoretical field of post-structuralism. Social constructionism, according to Willig (2001:7) is concerned with pointing out the fact that "...human experience, including perception, is mediated historically, culturally and linguistically." This means that the way (or rather ways) in which we experience reality is not an ahistorical given, but that it varies between different historical periods and between various cultural systems.

As such, the authors' perceptions and experiences must always be understood as a specific reading of social conditions, rather than simply a reflection of these conditions (Willig, 2001). Research that is conducted from within this paradigm is concerned with "...the various ways of constructing social reality that are available in a culture" (Willig, 2001:7). In this study the conceptual tools provided by social constructionist theory were used to explore the ways in which nurses constructed their experiences of working in the South African context.

\section{Design}

This study was informed by social constructionist theory; as such it was based on the use of ethnographic methods. Semi-structured, in-depth interviews were conducted with eight maternity ward nurses in a state hospital in the Western Cape, South Africa. This state hospital served all the participants who participated in the larger study on maternity mental health. The goal of the current study was to encourage nurses to articulate in their own words the psychological experience of being a maternity ward nurse.

\section{Procedure}

The nursing staff working at the hospital in question were approached by the interviewers after formal, written permission was obtained from the hospital. All of the nursing staff working in the maternity ward were asked to take part in the study. The goals of the study were explained and informed consent was obtained. The nurses were interviewed by the two first authors of the paper, who were graduate students in Psychology at the time. They also transcribed the interviews verbatim and analysed the data using (i) social constructionist grounded theory and (ii) Foucauldian discourse analysis.

\section{Participants}

All eight of the participants were "Coloured" (as classified under the Apartheid system), middleclass (in terms of socio-economic status), Afrikaans-speaking females. With regards to rank within

${ }^{1}$ The authors are mindful of the fact that the use of racial categories in South African scholarship is controversial. However, such categories are socially constructed and carry important social meanings (Swartz, Gibson \& Gelman, 2002). As such, the authors believe that, following the argument presented by Jewkes et al. (1998), it is impossible to conduct a meaningful analysis of our findings within the context of Post-Apartheid without making reference to previous racial classifications, since these still inform existing 
the hospital, five of the participants were sisters, two were staff-nurses, and one was a nursing assistant ${ }^{2}$. The eight participants interviewed represented two-thirds of the maternity ward nursing staff, which consisted of twelve people. One of the remaining twelve (a nurse) declined to take part (she did not want to give a reason for non-participation), and the remaining three members of staff (one sister, one nurse and one staff-nurse) were unavailable during the two-week period of interviewing. After the period of two weeks the researchers were clear that no new categories were emerging and that theoretical saturation seemed to have been achieved (Willig, 2001).

\section{Interviewers}

According to Charmaz' (1990) social constructionist grounded theory, the interviewers are viewed as co-constructors of the respondents' responses. In the current study there were two interviewers, both white, middle-class students, one male, age 25 (first author of this paper), and one female aged 21 (second author of this paper). The female interviewer interviewed 6 of the participants, 5 of them in individual interviews and 2 in a joint interview. The male interviewer interviewed the remaining 2 participants. It has become standard for feminist researchers and writers (Crawford \& Kimmel, 1999; Fonow \& Cook, 1991; Ramazanoglu \& Holland, 2002) to take their own subjectivity seriously, and to disclose those aspects of their own social location and identity which are thought to impact on the research process. For the purposes of this paper it is important to acknowledge that the ways in which the participants talked about their nursing experiences were certainly impacted upon by the fact that they were speaking to middle class white students from a traditionally white academic institution.

\section{Interviews}

Semi-structured interviews were used in this study. A basic interview schedule was agreed upon beforehand. Open-ended questions were used during the interviews. The goal was to allow the nursing staff as much freedom in articulating their psychological experience of being a nurse as was possible. All interviews were conducted in the maternity ward of the hospital, during their working hours, since it was felt that this setting would be the most conducive towards allowing the participants to articulate their professional identities.

\section{Analysis of Interviews}

Interviews were taped, and transcribed verbatim by the two first authors using Silverman's (1993) and Riessman's (1993) guidelines. Relevant sections were translated into English during the writing of this paper. The data was then analysed using the abbreviated version of social constructionist grounded theory (Charmaz, 1990, 1995). Grounded theory is a method that uses the data as a starting point, and which allows theory to emerge directly from the data, rather than using preconceived theoretical concepts to analyse the data. The social constructionist version of this particular method is different in the sense that it is based upon the contention that categories and theories do not so much emerge from the data, but are "...constructed by the researcher through an interaction with the data" (Willig, 2001:44). The emphasis in both versions, however, is on

power relations. In this paper then the category of 'black' will be used to refer to those designated as African under Apartheid racial classification. The category 'Coloured' is used to refer to South Africans said to be of diverse and mixed racial origins.

${ }^{2}$ Sisters occupy the highest rank in the nursing hierarchy, followed by staff nurses and then nurses. In the rest of this paper the term 'nurse' will be used exclusively in this sense, to denote the lowest member in the nursing hierarchy. 
creating a theory that is closely and organically linked with the data being analysed. The social constructionist version was chosen for this study since it has a better fit with the theoretical orientation of feminist poststructuralism.

Following Charmaz $(1990,1995)$ the transcribed interviews were first coded line-by-line. The research team then identified codes that seemed prominent. These codes were then used to conduct the second stage of analysis, the focused coding. Finally, links were established between categories as the research question was narrowed down and theory began to emerge (Pidgeon \& Henwood, 1997; Willig, 2001).

\section{Reliability and validity}

This study is qualitative and exploratory in nature. The sample is by no means representative (not even of this particular hospital), and no attempts will be made to generalise our findings to South Africa's nursing workforce. The authors are interested in highlighting prominent issues that emerged during this very detailed qualitative study in the hope that this can be the basis for further research in the area.

Since two nurses on the ward could not participate in the study, the eventual sample is slanted towards the experiences of the sisters in the maternity ward: five of the eight participants were sisters and only one was a nurse.

\section{Ethical considerations}

Ethical considerations were kept at the forefront throughout this study: the study adhered to all the requirements of the Subcommittee A of the Research Committee of Stellenbosch University. A long period of time was spent obtaining official permission from the hospital's management to conduct this study. Informed consent was obtained from all the nurses, and participation was strictly voluntary. Copies of the signed consent forms are available upon request. Pseudonyms were used for all the nurses and all references to real names during the interviews were omitted during transcription in order to ensure confidentiality.

\section{RESULTS AND DISCUSSION}

The three major categories that emerged from the grounded theory analysis were: the stress of caring (i.e. how difficult it is to be in a care-taking job); the problem with hospital hierarchies (the clearly delineated hierarchies that seemed to have an impact on how the work of caring was executed); and the aggressive feelings, thoughts and actions of nurses vis-à-vis their patients. In our analysis we will discuss these three categories in detail (by citing from the actual interviews and comparing our findings with the existing literature) and, following grounded theory principles, explore how the categories might be related. In the second paper, 'Violent nursing: A Foucauldian perspective on nursing in South Africa', these relationships will be theorised utilising a Foucauldian perspective.

\section{The stress of caring}

Caring is commonly identified world-wide as one of the core values for nurses to actualize in clinical practice (Arthur et al., 1999). However, it was apparent from the data that the participants all experienced severe stress that was intimately linked to their roles as caregivers within the context of the hospital.

Mandy: $\quad$ No, no, no...yes, most accept it like that, as a nurse you have to be strong, it is your job. But there are some of us that are fragile, who can't handle it... 
The nursing staff were all acutely aware of the fact that the work of nursing implied taking care of the other (the patient), and thus focusing on the other rather than on the self.

Jessica: $\quad$ Yes, it is, quite. I mean, hmmm, I think one must always place your patient's needs first. It doesn't matter whether I, when I come from home, whether it was unpleasant there or whatever, but then I musn't come to my job with that same... as we always say here if you have problems or whatever at home, you leave them there at the front gate, and tonight when you go home, you pick them up there. You shouldn't bring those...things to work, those things, because your patient suffers from that, so you must always, I think always put your patient, you must always put your patient first. (authors' emphasis)

Mandy: Yes...a good nurse for me is someone who puts her patient first. She won't first...put her...problems, or what is on her heart, she won't put that first. Patients will always be her first priority. The first thing, especially when you get to work, if you have problems at home you will leave them there, you don't bring your problems to work to take them out on your patients, because then you will make your patients unhappy with your actions. So, this is my opinion, the patient must always come first. (authors' emphasis)

There was a strong emphasis here on the idea that nurses should place their patients' interests before their own ('the patient must always come first') and subvert their own emotional needs while at work ('if you have problems at home you will leave them there'). This conceptualisation of nursing as an occupation that requires "extensive emotion work" (Bolton, 2001:85) was elaborated on by Belle (1982:500), who wrote that "...much of women's traditional work [work that involves caring] may be stressful and destructive of health." In fact, Belle (1982:500, quoting Colligan, Smith \& Hurrell), referred to a study where it was found that those in the health care professions were overrepresented in groups of people who sought treatment for mental health problems. Colligan et al. (quoted in Belle, 1982:500) commented that "...the responsibility of caring for and interacting with people who are ill...can be emotionally demanding, subjecting the health professional to considerable stress."

In practice, our participants found it very difficult to execute their care-taking responsibilities. They suggested two main sets of difficulties that they experienced in their roles as caretakers. The first set of difficulties had to do with patients resisting caring or failing to cooperate. The second set of difficulties had to do with their working conditions.

\section{Work environment}

The participants of the current study identified several aspects of their work environment which heightened the stressful nature of their roles as carers. One of the major issues in the work environment was considered to be the high workload.

Candy: When it is busy then...hmmm...sometimes then you feel very hmmm...(2) I mean when it gets really busy, then one feels so...(2) Overwhelmed yes, you feel so overworked, hey.

Charlene: So it was only me and the two sisters that worked this weekend...Yes, we worked hard. \{laughs $\}$

Charlene: When it gets that busy you have no choice you must concentrate on all the things you have to do, and...hmmm, when it gets that busy...especially with the women in labour, you have to do what you have to do. Understand? 
Sandy: $\quad$ There are some days when you don't even have time to go to the toilet. Then it is up and down, up and down the whole day.

Sandy: $\quad$ Oh, you get tired, you're busy!

Sandy: $\quad \quad \quad Y o u$ bread is there, but you don't even get a proper chance to eat.

Baby: $\quad$ You are busy, you are on your feet, you run up and down.

Mandy: Yes, we, hmmm, especially for night shift they can add an extra member of staff, maybe two, a sister and a nurse.

Jessica: $\quad$ Like the labour ward this past while, June, July and August, it is always busy.

Jessica: $\quad$ And things like that [newly born baby that died] always happen, those things always happen when you are at your busiest, and...you can't say, you are not really supposed to say but I was busy. (emphasis in original)

The stress caused by high workload was exacerbated by shortages of staff in the maternity ward.

Mandy: $\quad$ Yes, we have...very busy days. Especially night shift is difficult because we are only two, just a sister and a nurse. And sometimes we have to do caesarian, like an emergency at night...so, it is a bit, sometimes it is a bit difficult...

Mandy: =yes, it is hard. Yes, sometimes it is hard, especially when the ward is full, and we have caesarians and normal births. Because we often have cases like that, often we have patients that come in and then, there must be a sister with her during labour. And sometimes it is impossible.

Jessica: $\quad H m m m . . . I$ think if we had more, if we had more personnel...sometimes even if there are four of you [on duty], you can't always do everything, you badly want to do more for the patient but you don't always have the... So I feel if we maybe had more, hmmm, staff...hmmm, it could be, it would be quite...

Mandy: $\quad$ Oh my gosh, it drains you [being short-staffed], really... You can't wait to go home the next morning, all you want to do is sleep. Yes, it starts getting to you.

Mandy: $\quad$ Yes, that is why they rotate us [between different wards], because being in one place too long gets to you.

Candy: I won't say overworked, it is just that you, you have to do so much, you are understaffed and, various, you have to do a lot of thinking, and when you are alone.

Sandy: $\quad$ No, we are very few [staff].

Sandy: I think it [more staff] would help a lot. Especially at night we have only one sister and one nurse.

Jessica: $\quad$ Absolutely, we have always thought that the night-shift is under-staffed...Yes, I think one extra person would make a world of difference. (emphasis in original)

Apart from the high workload and shortage of staff, participants also mentioned a more general lack of resources such as dependable equipment:

Jolene: $\quad$.... and the baby was a bit limp at birth. So we struggled, and I saw ok, we won't, I won't be able to handle this on my own, so I phoned the doctor. When the doctor came we took the baby to the cradle...the...cradle we use for babies that have (to rest), but it didn't work, it wouldn't switch on. And we checked the plugs and 
everything, but it wouldn't go on, the lights and the heat and so on. And the scope didn't work properly, or it wasn't where it was supposed to be. Not available...

Interviewer: Does it happen often, problems with equipment?

Jolene: Often.

Many theorists have written about high levels of stress and burnout in health-care workers. Burnout can be defined as "...a syndrome which consists of three essential characteristics: emotional exhaustion, depersonalization, and low personal accomplishment" (Levert et al., 2000:36) In general, the literature seemed to suggest that burnout could be correlated with factors such as a high workload and lack of adequate support. More specifically, Bennett et al. (2001) found that two prominent factors which lead to heightened stress in health-care workers were a high workload and organisational factors within the hospital. Similarly, Steenkamp and Van der Merwe (1998:253) found that the two most prominent stressors in their sample of nursing staff were poor remuneration and high workload. Walker and Gibson (2004:4), who investigated the way in which nurses saw the implementation of the free care policy in South Africa, reported that $85 \%$ of the 113 nurses who completed their questionnaire felt that their workload had "...increased substantially", and that this increase seriously compromised "key elements of their professional practice". Levert et al. (2000), who did a study on South African nurses, also cited a high workload as a prominent factor in burnout.

\section{RESISTANT PATIENTS}

Our participants had clear expectations regarding the cooperation of patients:

Interviewer: And when you have to help a woman during labour, what would make it, what would you have them do, what would make it easier for you? Is there something=

Jolene: $\quad$ =they must just listen to what I say, and do as I tell them, but they... Ok, I don't know what it feels like to go through labour, I don't have children yet, so... Sometimes I just leave them, let them do their own thing, but usually I prefer for them to know...so I explain to them before labour what to expect and how they must behave. Then things go well. Otherwise it is a complete mess, and...and a stressful experience. (authors' emphasis)

Jolene expected patients to listen to her ('listen to what I say') and to 'do as [she told] them'. She exerted her authority by telling them exactly 'how they [should] behave.'. The repetition of the personal pronoun ('I') emphasised that the agency and the power in this setting belonged to her and to her alone.

Despite these expectations, almost all the nursing staff interviewed related incidents that were stressful due to the resistance (a refusal to co-operate) of patients:

Petunia: $\quad Y e s !$ It is nice, yes. But it makes one angry when the patients refuse to push [during labour]. \{laughs \} Do you understand?!

Candy: $\quad$...but, there are times that we, hmmm...sometimes when, if the patients are difficult, they don't want to cooperate...

Jessica: $\quad$ Yes...sometimes, because when the patient doesn't cooperate, you as a sister or a nurse know what the consequences could be when they don't cooperate. (Emphasis in original) 
Charlene: Oh yes, you often find them [nursing staff], who are hostile to patients because the patient, hmmm, takes so long to give birth.

Resistance on the part of the patients was often exercised through withholding cooperation at critical times.

Interviewer: But why do the patients refuse to push [during labour]?

Petunia: Ag, you know...these people, especially the black ${ }^{3}$ people, oh... They struggle...because labour. Because they don't want to push, or they say they want an operation. But you as a nurse knows what will happen to them if they don't want to push...the baby can die, or anything... If they refuse to push, you see, the baby's head is towards the front... but now they don't push. The baby can develop breathing problems... (emphasis in original)

Jessica: Hmmm...like when you ask them to push... They are, they are, they do, or you ask them not to push, because when you have finished...examining them and you can see that the head is not yet where it should be, you don't want them to push too early because they can tear or something can happen, and now you ask them not to push, and...they don't listen to you, they just do their own thing. (emphasis in original)

Baby: $\quad$ Yes, they refuse to push.

At other times resistance was expressed through patients being rude to the nursing staff:

Baby: It is only when someone upsets me, or makes me angry... Sometimes, the patients, they are unruly, yes. Or, you'll ask them a question and they'll give you a disrespectful answer, or they don't do what you, or they are just plain rude. (authors' emphasis)

Mandy: $\quad$ But then you also find many...patients that are rude... Drunk, patients that arrive there [hospital] drunk.

Mandy: $\quad Y e a h$, no man, it is not nice, it is not what...I mean you come to work with an open heart, you are cheerful and then you get here, and then you get patients who are rude. Ones that really insult you.

Baby displayed distress concerning patients who were 'rude', 'unruly' and 'disrespectful'. They had the power to 'upset' her mood and make her 'angry'.

Nor was it only the patients who could be rude and acted as stressors, their relatives or friends often fulfilled the same role:

Sandy: Yes, and Sunday, Sunday morning, we had a patient here. And her boyfriend, hmmm, got here. And she, the other nurse, said "morning, can we help?" And he replied, "no, what morning?" (imitating boyfriend). And that was just plain rude!

Sandy: That women, that sat on the bench for hours. The child got here, she came in. "Sister, why must my child stay here?" I replied, "my goodness lady, you've just come from the doctor". "Yes, but how do I know", and "she's the one", and...so I

3 Although we are aware of the fact that discrimination against patients on the basis of race is a very serious issue, especially in a post-Apartheid South Africa, and consequently demands further attention, it is not the central focus of this study, and as such will not be discussed in depth here. 
said, "no please come, let us go [sort it out]". She didn't have to be so rude! \{very aggrieved $\}$ [Emphasis in original]

Sometimes this struggle to obtain cooperation was linked to cultural and linguistic difficulties:

Candy: $\quad$ Language does...English and Afrikaans is ok, but when we get to the Xhosa patients for example...there we're going to struggle, because we...what do we tell the patients? And, and...especially if they are difficult patients, how do we tell them to push, and... It makes you feel powerless, yes, because you have so much you can do for the patient, but the patient does not understand you, you cannot reach the patient with your English or your Afrikaans language. (emphasis in original)

It is clear that the participants struggled with patients who withheld co-operation by refusing to obey orders, by questioning orders or by being rude and insulting. This is especially important in the light of findings by Winstanley and Richard (2002), who did a study on the correlation between burnout in nurses and their exposure to aggressive experiences. They defined these aggressive experiences as including physical assault, threatening behaviour, and verbal aggression, and noted that these included actions by the relatives and friends of patients. Winstanley and Richard (2002:302) found that “...emotional exhaustion and depersonalization were significantly higher in those staff more frequently victimized suggesting that aggressive encounters might lead to an increase in burnout." This argument was corroborated by Bennett et al. (2001:60), who found that anxiety in nurses is associated "...in particular...with conflicts at work with both patients and staff."

Also important for this analysis is the fact that the quotes cited above seemed to suggest that the nursing staff's notion of caring included the assumption that to care for a patient also implied to have control over a patient. The participants suggested that their job became very stressful when the patients that they had to care for did not allow them to assume control over them or over the situation.

The participants seemed to find it difficult to fulfil their roles as carers: they mainly ascribed the stressful nature of their job to "difficult" patients and a work environment characterised by an immense workload, a shortage of staff and a dearth of technical and financial resources.

\section{Hospital hierarchies}

The second major theme that emerged in the interviews had to do with the different hierarchies that seemed to be operative in the hospital. There was a clear differentiation between different levels of staff, but the nursing staff also distinguished between different levels of patients within the hospital hierarchy.

\section{Staff hierarchies}

It was clear from the outset that our participants were very aware of their own position within the hospital's hierarchy, as well as the position of everyone else relative to them, including but not limited to patients. Within the hospital chain of command, a nurse and a staff nurse were subordinated to a sister. Both Mandy (staff nurse) and Charlene (nurse) displayed this awareness:

Mandy: Yes! We are not supposed, especially the nurses are not supposed to be alone, because one of the sisters from another ward, we phone them, when we see that the patient is starting to go into labour, she comes to help, she catches the baby. (authors' emphasis) 
Charlene: And, at certain times of the year you find that we have many people in labour at the same time. And then it is, then I feel very unhappy especially if the sister starts scolding you. And, hmmm, you ward comes to a standstill, and and and and, then she starts getting difficult. Because the patients are coming in, and they have to be busy with the ones in labour, then it is a tough day for you as a nurse. (authors' emphasis)

Charlene illustrated in this quote the ability of the sister to exercise power over her by expressing aggression ('if the sister starts scolding you', 'starts getting difficult'). Furthermore, she acknowledged clearly that this was distressing to her ('feel very unhappy', 'a tough day for you as a nurse'). Sisters, conversely, were very aware of their position of authority relative to the nurse and the staff nurse. Jolene, a sister, in the following extract reflected on an incident where her nursing assistant did not show up in time to help with a patient in labour:

Jolene: $\quad$ No, I, I just started off on the wrong foot...because...(3) hmmm, when we came on duty there was a patient that was very close to labour... and it was time for the baby to be born, and hmmm...I called her [the nurse], because she is supposed to come help me. And when she got there, she said to me, she asked, why did I call her, can't I do it on my own? And...no one has ever spoken to me like that. To me, it is a...I'm shocked... (authors' emphasis)

The nurse, who was supposed to help Jolene during the labour process, told her that she (Jolene) should do it on her own ('can't [you] do it on [your] own'). Notice Jolene's complete astonishment at this; she remarked that 'no one had ever spoken to her like that' and that she was 'shocked'.

Even though sisters were placed in a position of authority over the other nursing staff and had the duty to report any deviant behaviour, they too were subjected to informal sanctions from the nurses below them:

Jessica: $\quad H m m m$...like, when someone does something they aren't supposed to ... they have to be spoken to regarding this and whatever, and, hmmm ... it is your duty as a sister to write a report about it, and so on... That person will come back and ask, who implicated me in this, and people will tell her, no, it was Sister (X). So eventually, that person comes back to you...

Interviewer: Hmmm ... is this a stressful part of being a sister?

Jessica: Oh yes! It is, it's terrible. And at certain times, there are so many little things happening around here that, hmmm... and no one has the courage to...to write a report about it or whatever...because it comes back to you and that person blames you for it. So it is ... it is quite... it is a very stressful thing to ... (authors' emphasis)

Jessica, the sister in command, feared to exert her authority over the nurses ('have to be spoken to', 'write a report'), because she knew that there would be informal retaliation (' $\mathrm{t}$ ]hat person will come back', 'that person blames you for it'). Clearly this was a very distressing aspect ('[i]t is, it's terrible') of her position in the hierarchy, since she felt, on the one hand, duty-bound to report deviant behaviour, but feared, on the other hand, that this would compromise her working relationship with her subordinates.

But the nursing staff also reported being subordinated to the doctors:

Candy: And, hmmm, some of the doctors come down on you... and one of the doctors came to talk to me, and he was really angry, and he, he was, hmmm...difficult... and he, 
hmmm...he, came down on me, so badly that I, hmmm, I was left shaking and I...from that point on my day was...didn't run very smoothly. (emphasis in original)

Here Candy, who is a sister and therefore relatively high in the hospital hierarchy, displayed an awareness of the doctor's superior status and authority. When the doctor criticized her ('come down on you', 'was really angry', 'difficult') it was so distressing that it left her 'shaking', and marred the rest of her day ('my day was...didn't run very smoothly'). The crucial point here is that Candy did not cast the doctor's actions as bad or unusual. Her implicit assumption seemed to be that it was the doctor's priviledge to exert his authority in this manner.

\section{Patient hierarchies}

The participants also clearly distinguished between different groups of patients and accordingly decided how a patient should be cared for. The first discernable group of patients were the private patients, who were sometimes treated with more and sometimes with less respect than other patients:

Jessica: $\quad$ Like, hmmm, often, private patients... Ok, they, you understand, they pay that little bit more than a, than a normal patient. And then they expect to have a little bit more attention or whatever...

Petunia: It is just now and then, especially private [patients], that is actually problematic. Private. Because they always find something...wrong...with the hospital, it's like, you know, private patients have more. If you go private everything is there. And patients (expect) according to that. Understand? So, for instance, a doctor will bring his [private] patient, and then he will expect things to be a certain way, understand? And then it can maybe be a problem. (emphasis in original)

This quote from Petunia is indicative of the ambivalent feelings that were sometimes harboured about private patients. She displayed an awareness of their higher socioeconomic status ('private patients have more'), yet this seemed to make them more demanding and harder to work with ('always find something...wrong...with the hospital', 'expect to have a little bit more attention...').

Participants also referred to patients who lacked resources:

Interviewer: And, when they don't book? Like, say for instance the person that came from Transkei, what did she bring with her?

Petunia: $\quad$ I don't know. She actually had nothing with her.

Jolene: $\quad O k$, I don't distinguish, hmmm, I won't say I make a distinction between them, I try to treat everyone the same. I mean, there's nothing I can do about it anyway, and it makes me think, that could have been me, I could be living with that person's circumstances, or whatever. So, afterwards I will just tell them politely, wash yourself, or...you don't smell nice, do something, use some soap or so, that's all. I mean there's nothing else I can do.

Another group of patients that many of the respondents referred to were black patients from the Transkei:

Petunia: =yes, often! Every second one [comes from Transkei]...They, when it is nine months they jump on the bus. We always say when, when they walk in here, then we say wow, the bus has arrived again! \{laughs\} But we know they are from Transkei, you 
understand... Because then things aren't so expensive...costs and so on. But if you had to be born down there [Transkei], then it is big money. I, I don't know if that is really true, but that's the story I've heard...no, no, no, they do that. They, the people, the blacks. They stay in Transkei, go to the clinic there. When it's time to go into labour, they come up here.

Interviewer: Do they come here? To Cape Town, Stellenbosch area?

Petunia: Yes...because they...they inflate our statistics, and they make our budget, they deplete our budget. Understand? (emphasis in original)

Petunia claimed here that the black patients from Transkei had a negative impact on hospital statistics ('they inflate our statistics') and finances ('they deplete our budget').

Jessica claimed that she experienced black patients as being disobedient and independent:

Jessica: $\quad$...they don't listen to you, they just do their own thing. Especially, and I don't want to discriminate, but the black people. \{last part in whisper\} ...I don't think, I don't think it is an issue of language, I think they are just like...they all have that same manner where they go sit on the bed on all fours...And they push like there's no tomorrow.

Interviewer: On all fours?

Jessica: $\quad Y e s . . . t h e y$ push on all fours. And that makes things a bit difficult because you have to be here underneath them...Hmmm, I don't know if it is part of their culture, or if they... if it is... I don't know, but in any case, they sit, they all do that. They go on all fours and they push like there's no tomorrow. Even if you...no, they do... And it makes you a bit angry sometimes, because they...they don't cooperate, and anything can happen if they, because they are upside down. (emphasis in original)

Jessica recounted here the perceived unruliness of black patients ('...they don't listen to you, they just do their own thing'). She focused on the different position that they assumed during labour ('on the bed on all fours'), a difference that was implicitly deigned as inferior ('part of their culture'). This unruliness represented a challenge to Jessica's authority as a sister ('they don't cooperate'), and clearly triggered feelings of resentment and hostility ('it makes you a bit angry sometimes'), since this behaviour was not at all part of the accepted script that regulated interactions between sister and patient ('they are upside down'). Sometimes there seemed to be no particular reason for the discrimination:

Jolene: $\quad$ Sometimes they discriminate against patients...No sometimes they don't treat the blacks...the same.

It is important to note that not only black patients were seen as unruly. Any patient could potentially be placed in this category.

Jessica: But now some of them, when the pain starts getting intense, they go back and get in their beds again. So they lie there, perhaps next to someone else who is about to go into labour, maybe a young girl or someone like that. And they stress that poor girl out with the racket they put up. (emphasis in original)

Jessica: $\quad$ The patient, you tell her...move down in your bed! Because, as the pain gets worse they keep shifting up until it looks like they want to climb out the walls. So you have to tell them again, shift down your bum, open your legs a little, and so... (emphasis in original) 
The participants also referred to a group of younger patients. They claimed that these patients were not supposed to be pregnant:

Jessica: Hmmm...you, of course you are not happy with it [young girls in labour], I mean they are still young, they are, physically they are not yet ready for it, and mentally they are not ready yet, I mean, to be a mom, or whatever. So, it is quite...you are not happy... with it. (authors' emphasis)

Notice that Jessica expressed here the belief that it is completely natural for herself to be unhappy with young pregnant women ("of course you are not happy with it"). Rather than providing evidence for her beliefs, she invoked medical, specifically developmental, discourse to back them up when she stated that their bodies and minds were not ready for pregnancy at that age. Mandy discussed the way in which these young girls are often treated:

Mandy: $\quad$ Especially like the young girls that come here, we get a lot of them that are 16, 17, $18 . .$. "Why didn't you listen to your mother?" Especially when they, hmmm, when they are in pain, then they are, then they [nursing staff] are very critical towards them, hmmm... They attack them, try to hurt them verbally, when actually it is a time they need support, when they are in pain... Or children that come in that already had an abortion. "Why did you do this?", and "why didn't you wait until you are married before having children?". And these are not things that are nice to hear, they hurt.

It is clear that young girls occupied a very marginalized position within the hospital and patient hierarchies. The nursing staff was openly critical towards them ('they are very critical'), they attacked them 'verbally' ('these are not things that are nice to hear, they hurt') and emotionally ('Why did you do this? Why didn't you wait until you were married before having children?'), even though some of them were in a highly vulnerable state ('children that...already had an abortion').

One participant spoke about the personal risk involved in caring for an HIV patient, echoing findings by Kline (2003):

Petunia: Hmmm...do you know what else can be a bit stressful? The...patients with HIV, the HIV patients...Yes. (3) Because, see one does not always come, you, you, you, hmmm, sometimes they come in, and they go directly into labour, you understand? So they didn't have medication. That can be, that is quite a problem. So then, you must check, often you have to, often, you actually have to take precautions when you work with them, you see? ...For the blood, and so on. But it can work on your nerves, because sometimes there are so many of them.

In summary, it seems that patients were assigned to different categories and were treated accordingly. The nursing staff regarded certain groups of patients as problematic: private patients, poor patients, black patients, dirty patients, young patients, and HIV patients. In the previous section it was asserted that caring for patients involved a certain amount of control over patients. The respondents seemed to also suggest that there were certain categories of patients that could not be controlled and therefore were more difficult to take care of.

There was, in other words, a complex and dynamic interplay between the nursing staff and the patients. Numerous and complex power struggles took place within the hospital: amongst the nursing staff, between the nursing staff and the patients, and between the nursing staff and higher authorities within the hospital, such as doctors. Sisters, whilst having authority over nurses and staff-nurses, were often reluctant to exert this power for fear of informal retaliation. Many of the 
nurses and staff-nurses seemed to exercise power over the sisters by withholding their cooperation at critical times or by informally sanctioning them on a social level. All of the nursing staff reported being dominated by the doctors.

The nursing staff, who typically assumed control over patients, were also open to reprisal from patients. Patients exercised their power through being rude or refusing to cooperate; even their relatives sometimes abused and intimidated the nursing staff. The amount of stress and distress that seemed to be evoked by and contained within all these hierarchy-bound interactions, coupled with the stressful role of carer, a high workload and lack of adequate support, were reported to be the most important stressors in the professional lives of our participants.

\section{Aggressive feelings, thoughts and actions}

All the participants reported being aware of nursing staff having aggressive thoughts or feelings about patients.

Candy: But sometimes you just feel like, then you think, oh, you just want to assault that patient, if the patient won't push and so on. \{strong emotion\} (emphasis in original)

Jessica: $\quad$...but they didn't do their part, so you...sometimes it makes you...hmmm, you get this thought in your head, you want to...tell the patient what you think, but then I tell myself no no no no. It's not polite what you are thinking now, what you want to say to this patient. Then you must rein yourself in...you can't talk to the patient like that. (emphasis in original)

Jolene: $\quad$ And... and you don't care, you want to work, but it seems as if they [other nursing staff] don't want to work. By the time patients come in they are already angry.

Interviewer: And, hmmm, how does working with an HIV positive patient make you feel?

Petunia: I get angry!... And and I get really, I get angry at [HIV positive] people who... [have babies] (emphasis in original)

Jessica: Hmmm, that is, as far as I know, I know often the people have such negative... perceptions of the hospital, or they have a ...they clash with one of the nurses or whatever... (emphasis in original)

There were also many reports of these feelings or thoughts being acted out:

Jessica: $\quad$....and then I have to raise my voice to her, and tell her, no no no no my girl, you must please, you can't lie here, you are disturbing the others, just get out of this bed and go back to the labour ward... So you need to raise your voice to them now and then. You don't mean to...but sometimes it is the only thing that works. (emphasis in original)

Mandy: $\quad$ Oh, yes. You aren't supposed to, but sometimes you find, hmmm, nurses that in my opinion don't treat patients well... Hmmm, that are rude to patients. (authors' emphasis)

Jessica: $\quad Y o u$ just have to raise your voice, that's all you can do. I mean you can't, what else are you going to do? \{laughs\} (emphasis in original)

Mandy: $\quad$...they [nursing staff] are very critical towards them. They attack them, try to hurt them verbally...And these are not things that are nice to hear, they hurt. 
Sandy: $\quad$ Oh my goodness. You just have to raise your voice. Show a bit of anger... Yeah we raise them, we do.

Petunia: I mean, there are some times when you get tough [with the patients], you understand, but that's just human.

Charlene: Yes, I've often seen that...seen a sister scold a patient. And then, I am unhappy about it, but I don't talk about it, I keep it to myself.

Mandy: $\quad$ And I've often seen that, they give them [rude patients], the nurse will give him an answer, but I mean he should have known what's coming. \{laughs\}

Charlene: $\quad$...so I will tell her, don't worry, the sister only scolded you because your baby is so important. Because if the sister didn't try to deliver your baby, the baby could have died, or something could have happened to him...So, the sister didn't want that to happen, that's why she was a bit rude to you and so on.

Sometimes, however, these feelings manifested in the withholding of care.

Jolene: $\quad$ Sometimes I leave them, let them do their own thing. (authors' emphasis)

Jessica: $\quad$...and sometimes it does create tension, and you feel like they don't appreciate what it is you do for them, or whatever. And, hmmm, sometimes I feel like, I don't want to go into that...that room with that patient. So sometimes I just feel like walking past...

Jolene: It happens quite often [private patients who are very demanding]...And it, it just creates an atmosphere and then...the sisters will avoid those people...for a whole evening, leave them alone, without going and checking to see if they are ok.

Petunia: $\quad$...you won't, with difficult patients, you don't want to help them. Because they didn't even go to the trouble of coming to the clinic. (emphasis in original)

Jolene: It happens quite often [patients who cannot understand Afrikaans or English]... then...we just leave them to give birth on their own. We do stand there, but they have to push on their own, because they don't understand what you want them to do. So then they just push and the child gets born...

It seems then that apart from the fact that nursing staff often had aggressive thoughts or feelings about patients, these thoughts and feelings were also at times acted out: clear instances of verbal abuse, emotional abuse, and the withholding of care were reported. These findings, and indeed some of those discussed earlier, corroborate research conducted by Abrahams et al. (2001) and Jewkes et al. (1998), who examined the phenomenon of patient abuse and its impact on healthseeking behaviour in South Africa. Despite the fact that Abrahams et al. and Jewkes et al. asserted that patient abuse seems to be ritualised and sanctioned in South African hospitals, these are the only published works that deal specifically with the abuse of patients by nurses in South Africa. However, this phenomenon has frequently been highlighted in the international literature on nursing (e.g. Hirst, 1999; Pillemer \& Bachman-Prehn, 1991; Pillemer \& Moore, 1989). These international studies focused primarily on patient abuse in the context of caring for the aged and for psychiatric patients. There is also a plethora of literature aimed at nursing professionals that discuss patient abuse within the context of the nurse-patient relationship (Brindley, 1999; Carter, 1999; Clarke, 1999; Fitzgerald, 2003; Golding \& Clear, 2001; Gulland, 1999; Nazarko, 2001; Neal, 1999; Powell \& Tucker, 2004; Smith, 1993; White, 1999).

Abrahams et al. (2001) and Jewkes et al. (1998) first interviewed patients, but when they found several instances of physical, verbal and emotional abuse, as well as neglect of patients, they 
broadened their study to include the nursing staff. They noted that nurses differentiated between different types of patients, for instance patients who were 'dirty', 'cheeky', 'very obstreperous', 'rude', 'hostile' and 'abusive' (Jewkes et al., 1998:1790). Abuse was often directed at teenage patients (1998:1786), patients from rural areas such as Ciskei and Transkei (1998:1791), and poor, marginalized women in general (1998:1792). The nurses themselves, when interviewed, identified a host of issues which potentially contributed to this phenomenon: organisational issues (they did not elaborate on this), the fact that they were overworked, and experienced shortage of staff and equipment (1998:1789), being abused by patients (1998:1788), and a “...perceived need to assert control over the environment and patients" (1998:1788). Crucially, Jewkes et al. (1998:1789) identified a link between control and power. They noted that nurses often motivated their abuse of patients through "...concerns for [the health of] the baby" (1998:1788), and that consequently "...the boundaries between control and punishment were often blurred" (1998:1789). The findings of the current study thus supported the findings of Jewkes et al. (1998), but in addition clearly highlighted the fact that aggressive thoughts, feelings and behaviours occurred in the context of an environment that was characterised by rigid hierarchies and implicit and explicit expectations of how caring involved control.

\section{CONCLUSION}

Several studies have shown that all health-care professionals working in the public sector in South Africa, and especially nursing professionals, suffer from high levels of stress and are at increased risk of burnout. Many researchers have argued that this has important implications for the nursepatient relationship, and ultimately for the health-seeking practices of South Africans. The authors of this paper contend furthermore that mental health-care professionals in South Africa such as psychologists, counselors and social workers need to understand the way in which nursing professionals experience their work, since they have to provide support for these workers.

The current study focused on exploring these conditions through in-depth, qualitative analysis of how the maternity ward nursing staff in one state hospital in the Western Cape constructed their day-to-day experiences. In a grounded theory analysis of the interviews three major but related issues emerged. In the first section of the paper it was argued that participants experienced their work of taking care of patients as extremely stressful. This was on the one hand due to working conditions in the hospital, but on the other hand the nursing staff also felt under particular pressure when they felt that patients were resisting their care, i.e. not following their instructions. It seemed clear that the nurses understood taking control of the patients as part and parcel of their care-taking task. In the second section we highlighted how important the hierarchies in the hospital seemed to be for nursing staff: not only were they able to delineate clear differences in status between different medical workers, they also distinguished between different categories of patients. Most remarkable was that those patients and staff members who were considered to be the lowest on the different hierarchies were also the ones who were regarded to be out of control (not obeying orders or resisting authority). In the last section we showed how many of the nurses reported that such patients (those who were regarded to be out of control, disobedient) often elicited aggressive thoughts, feelings and even actions in nursing staff, findings that corroborate the studies of Abrahams et al. (2001) and Jewkes et al. (1998).

Following grounded theory, it is important to explore how the different core categories can be related to each other. It can be argued that the central underlying concept to all three core categories is the concept of power. First, it seems clear that nurses constructed the caring relationship as a power relationship: according to them to take care of a patient meant to assume control of the patient. These power relationships seemed to be formalized in a hierarchy that was 
sometimes explicit (different job descriptions of medical workers) and sometimes more unspoken (different categories of patients). The power struggles that followed from such a hierarchical system (where the very business of the institution - caring - seemed to be based on assuming control) were complex and multifaceted. The exertion of power was often followed or pre-empted by resistance, followed by even more measures to control. In the end these power struggles manifested in the aggressive feelings, thoughts and actions that the nursing staff had about patients. This could, in turn, be expected to impact on the nurse-patient relationship and ultimately also on help-seeking behaviour. These findings are not unique: international studies (Brown, 2003; Lay, 2003; Lay, Wahlstrom \& Brown, 1996; Lupton \& Fenwick, 2001; Peckover, 2002; Steenkamp \& van der Merwe, 1998; Wilson, 2001) and local studies (Abrahams et al., 2001; Jewkes et al., 1998) have focused on the power relations inherent in the nurse-patient relationship in maternity wards.

In the second part of the paper, the authors will use Foucauldian theory in an attempt to further illuminate the importance of power relationships within an institution of care such as a hospital. Foucault's work has been extensively used in discussions of power relationships in the context of the medical and nursing professions (e.g. Brown, 2003; Ceci, 2003, 2004; Gastaldo \& Holmes, 1999; Georges \& McGuire, 2004; Gilbert, 1995; Heartfield, 1996; Huntington \& Gilmour, 2001; Kettunen, Poskiparta \& Gerlander, 2002; Lay, 2003; Lay, Wahlstrom \& Brown, 1996; Lupton \& Fenwick, 2001; Peckover, 2002; Porter, 1996; Pryce, 2000; Riley \& Manias, 2002; Wilson, 2001). Interestingly, however, none of these studies used a Foucauldian framework to analyse the widelyreported phenomenon of patient abuse. Also, despite the recent proliferation of nursing research in South Africa, South African nursing in general (and patient abuse specifically) has not yet been analysed using a Foucauldian perspective. Gibson (2004) wrote about this as a "...gap in the gaze in South African hospitals", while Butchart (1997:179) referred to "...the failure of Foucault to take hold in the South African socio-medical sciences".

The results as reported here, however, clearly indicate that mental health professionals working with nurses in the public sector should on the one hand focus on being advocates for changing the working conditions of nurses (which is characterised by a high workload, lack of adequate support, and a dearth of technical and financial resources), but on the other hand that they should be working on creating safe spaces where issues related to the stressfulness of caring can be explored and addressed. In such spaces psychologists and social workers should be particularly mindful of how this kind of stress manifests in and is exacerbated by complicated power relationships, often leading to aggressive feelings, thoughts and behaviours.

\section{REFERENCES}

ABRAHAMS, N., JEWKES, R. \& MVO, Z. 2001. Health care-seeking practices of pregnant women and the role of the midwife in Cape Town, South Africa. Journal of Midwifery \& Women's Health, 46(4):240-247.

ALTUN, I. 2002. Burnout and nurses' personal and professional values. Nursing Ethics, 9(3):269-278.

ARTHUR, D., PANG, S., WONG, T., ALEXANDER, M.F., DRURY, J., EASTWOOD, H., JOHANSSON, I., JOOSTE, K., NAUDE, M., NOH, C.H., O'BRIEN, O., SOHNG, K.Y., STEVENSON, G.R., SY-SINDA, M.T., THORNE, S., VAN DER WAL, D. \& XIAO, S. 1999. Caring attributes, professional self concept and technological influences in a sample of Registered Nurses in eleven countries. International Journal of Nursing Studies, 36:387-396. 
BELLE, D. 1982. The Stress of Caring: Women as Providers of Social Support. In: GOLDBERGER, L. \& BREZNITZ, S. (eds) Handbook of Stress. New York: Free Press.

BENNETT, P., LOWE, R., MATTHEWS, V., DOURALI, A. \& TATTERSALL, A. 2001. Stress in nursing: coping, managerial support and work demand. Stress and Health, 17:55-63.

BILLETER-KOPONEN, S. \& FREDÉN, L. 2005. Long-term stress, burnout and patient-nurse relations: qualitative interview study about nurses' experiences. Scandinavian Journal of Caring Sciences, 19(1):20-28.

BOLTON, S.C. 2001. Changing faces: nurses as emotional jugglers. Sociology of Health \& Illness, 3(1):85-100.

BRINDLEY, M. 1999. Doctor should end his jibes at hard-working nurses... 'What the doctor witnessed', February 24, p.27. Nursing Times, 95(11):18.

BROWN, A.M. 2003. Foucauldian Perspectives on Midwifery Practices and Education. Internet Journal of Advanced Nursing Practice, 6(1):15-30.

BURMEISTER-NEL, H. 2005. The psychological experience of pregnancy: A review of the literature. Stellenbosch: University of Stellenbosch. (M thesis)

BUTCHART, A. 1997. Objects without origins: Foucault in South African socio-medical science. South African Journal of Psychology, 27(2):101-110.

CARTER, P. 1999. Rotten apples. Nursing Times, 95(8):28-30.

CECI, C. 2003. Midnight reckonings: on a question of knowledge and nursing. Nursing Philosophy, 4(1):61-76.

CECI, C. 2004. Nursing, knowledge and power: A case analysis. Social Science \& Medicine, 59(9):1879-1889.

CHARMAZ, K. 1990. “Discovering”, chronic illness: Using grounded theory. Social Science \& Medicine, 30:1161-1172.

CHARMAZ, K. 1995. Grounded theory: Rethinking methods in psychology. London: Sage.

CILLIERS, F. 2002. Salutogenic coping with burnout among nurses: A qualitative study. South African Journal of Labour Relations, Summer Issue:61-79.

CLARKE, L. 1999. Darkness visible...shedding light on nurse abuse of people with disabilities. Nursing Times, 95(34):36-37.

CORBET-OWEN, C. \& KRUGER, L. 2002. The health system and emotional care: Validating the many meanings of pregnancy loss. Families, Systems \& Health.

COX, K.B. 2001. The effects of unit morale and interpersonal relations on conflict in the nursing unit. Journal of Advanced Nursing, 35(1):17-25.

CRAWFORD, M. \& KIMMEL, E. 1999. Promoting methodological diversity in feminist research. Psychology of Women Quarterly, 23(1):1-7.

FITZGERALD, G. 2003. Listen up. Good nurses need not fear a civil standard of proof. Nursing Times, 99(26):16.

FONOW, M.M. \& COOK, J.A. 1991. Back to the future: A look at the second wave of feminist epistemology and methodology. In: FONOW, M.M. \& COOK, J.A. (eds) Beyond methodology: Feminist scholarship as lived research. Bloomington: Indiana University Press. 
GASTALDO, D. \& HOLMES, D. 1999. Foucault and nursing: a history of the present. Nursing Inquiry, 6(4):231-240.

GAVEY, N. 1989. Feminist Poststructuralism and Discourse Analysis. Psychology of Women Quarterly, 13(4):459-475.

GEORGES, J.M. \& MCGUIRE, S. 2004. Deconstructing Clinical Pathways: Mapping the Landscape of Health Care. Advances in Nursing Science, 27(1):2-11.

GIBSON, D. 2004. The gaps in the gaze in South African hospitals. Social Science \& Medicine, 59(10):2013-2024.

GILBERT, T. 1995. Nursing: empowerment and the problem of power. Journal of Advanced Nursing, 21(5):865-871.

GOLDING, L. \& CLEAR, D. 2001. A proactive approach to preventing abuse. Nursing Times, 97(43):32-33.

GROSSMAN, F.K., KRUGER, L. \& MOORE, R.P. 1999. Reflections on a feminist research project. Subjectivity and the wish for intimacy and equality. Psychology of Women Quarterly, 23:117-135.

GROSSMAN, F.K., KRUGER, L. \& MOORE, R.P. 2000. Reflections on a feminist research project. Subjectivity and the wish for intimacy and equality. In Kimmel, E.B. \& Crawford, M. (eds) Innovations in feminist psychological research. Cambridge: Cambridge University Press.

GULLAND, A. 1999. Clear and present danger. Nursing Times, 95(47):16-17.

HEARTFIELD, M. 1996. Nursing documentation and nursing practice: a discourse analysis. Journal of Advanced Nursing, 24(1):98-103.

HIRST, S.P. 1999. Resident abuse within the culture of long-term institutions. Alberta: University of Alberta. (D thesis)

HUNTINGTON, A.D. \& GILMOUR, J.A. 2001. Re-thinking representations, re-writing nursing texts: possibilities through feminist and Foucauldian thought. Journal of Advanced Nursing, 35(6):902-908.

JEWKES, R., ABRAHAMS, N. \& MVO, Z. 1998. Why do nurses abuse patients? Reflections from South African obstetric services. Social Science and Medicine, 47(11):1781-1795.

KETTUNEN, T., POSKIPARTA, M. \& GERLANDER, M. 2002. Nurse-patient power relationship: preliminary evidence of patients' power messages. Patient Education and Counseling, 47(2):101-113.

KLINE, D.S. 2003. Push and pull factors in international migration. Journal of Nursing Scholarship, Second Quarter:107-111.

KRUGER, L. 2003. Narrating motherhood: the transformative potential of individual stories. South African Journal of Psychology, 33(4):198-205.

KRUGER, L. \& VAN DER SPUY, T.M. 2005. Obscuring the pregnant body: Losing touch "with the hard surfaces of life" as methodological problem or substantive issue. South African Journal of Psychology. In print.

LAY, M.M. 2003. Midwifery on Trial: Balancing Privacy Rights and Health Concerns after Roe v. Wade. Quarterly Journal of Speech, 89(1):60-77. 
LAY, M.M., WAHLSTROM, B.J. \& BROWN, C. 1996. The Rhetoric of Midwifery: Conflicts and Conversations in the Minnesota Home Birth Community in the 1990s. Quarterly Journal of Speech, 82(4):383-401.

LAZARUS, J. \& KRUGER, L. 2004. Small meetings: Reflections on the application of psychodynamic thought in community work with low-income South African children. Part 1: Reflections on the literature. Psychoanalytic Psychotherapy in South Africa, 12(1):52-73.

LAZARUS, J. \& KRUGER, L. 2004a. Small meetings: Reflections on the application of psychodynamic thought in community work with low-income South African children. Part 2: Reflections on a case study. Psychoanalytic Psychotherapy in South Africa, 12(2).

LEVERT, T., LUCAS, M. \& ORTLEPP, K. 2000. Burnout in psychiatric nurses: contributions of the work environment and a Sense of Coherence. South African Journal of Psychology, 30(2):36-43.

LUPTON, D. \& FENWICK, J. 2001. 'They've forgotten that I'm the mum': Constructing and practising motherhood in special care nurseries. Social Science and Medicine, 53(8):1011-1021.

NAZARKO, L. 2001. See, hear - then speak out...every nurse who witnesses abuse or neglect has a duty to speak out. Nursing Standard, 15(20):22.

NEAL, K. 1999. When power corrupts. Nursing Times, 95(8):29.

PECKOVER, S. 2002. Supporting and policing mothers: an analysis of the disciplinary practices of health visiting. Journal of Advanced Nursing, 38(4):369-377.

PETERSEN, I. \& SWARTZ, L. 2002. Primary health care in the era of HIV/AIDS. Some implications for health systems reform. Social Science \& Medicine, 55(6):1005-1013.

PIDGEON, N. \& HENWOOD, K. 1997. Using grounded theory in psychological research. In: HAYES, N. (ed) Doing Qualitative Analysis in Psychology. Hove: Psychology Press.

PILLEMER, K. \& BACHMAN-PREHN, R. 1991. Helping and hurting. Research on Aging, 13(1):74-96.

PILLEMER, K. \& MOORE, D.W. 1989. Abuse of patients in nursing homes: findings from a survey of staff. Gerontologist, 29(3):314-320.

PORTER, S. 1996. Contra-Foucault: Soldiers, Nurses and Power. Sociology, 30(1):59-71.

POWELL, S. \& TUCKER, R. 2004. The way we were: nurses recall 'shameful' incidents of restraint. Learning Disability Practice, 7(4):3-5.

PRYCE, A. 2000. Frequent observations: sexualities, self-surveillance, confession and the construction of the active patient. Nursing Enquiry, 7(2):103-111.

RAMAZANOGLU, C. \& HOLLAND, J. 2002. Feminist methodology: challenges and choices. London: Sage.

RIESSMAN, C.K. 1993. Narrative Analysis. Qualitative research methods series 30. Newbury Park, CA: Sage Publications.

RILEY, R. \& MANIAS, E. 2002. Foucault could have been an operating room nurse. Journal of Advanced Nursing, 39(4):316-324.

SAND, A. 2003. Nurses' personalities, nursing-related qualities and work satisfaction: a 10-year perspective. Journal of Clinical Nursing, 12:177-187. 
SILVERMAN, D. 1993. Interpreting qualitative data. Methods for analyzing talk, text and interaction. London: Sage.

SMIT, J. 2002. A feminist exploration of the concept of Postpartum Depression. Stellenbosch: University of Stellenbosch. (M thesis)

SMITH, V.M. 1993. Real issues of abuse...survey on abuse of patients by nurses. Registered Nurse, 5(6):5.

SPIES, D. 2001. The coping mechanisms of female farmworkers in the Western Cape: a grounded theory study. Stellenbosch: University of Stellenbosch. (M thesis)

STEENKAMP, W.C. \& VAN DER MERWE, A.E. 1998. The psychosocial functioning of nurses in a burn unit. Burns, 24(3):253-258.

SWARTZ, L., GIBSON, K. \& GELMAN, T. (eds) 2002. Reflective practice: Psychodynamic ideas in the community. Cape Town: Human Sciences Research Council.

TSELEBIS, A. \& MOULOU, A. 2001. Burnout versus depression and sense of coherence: Study of Greek nursing staff. Nursing and Health Science, 3:69-71.

VAN DER WALT, 1998. Nurses and their work in tuberculosis control in the Western Cape: Too close for comfort. Cape Town: University of Cape Town. (D Thesis)

VAN DER WALT, H.M. \& SWARTZ, L. 2002. Task orientated nursing in a tuberculosis control programme in South Africa: where does it come from and what keeps it going? Social Science \& Medicine, 54:1001-1009.

VAN WYK, B. 2005. Caring for caregivers: psychodynamic interventions for staff-support for primary health care workers. Stellenbosch: Stellenbosch University. (D Thesis)

WALKER, L. \& GIBSON, L. 2004. 'We are bitter but we are satisfied': nurses as street-level bureaucrats in South Africa. Social Science and Medicine, 59(6):1251-1261.

WHITE, C. 1999. How abuse happens. Nursing Times, 95(8):26-27.

WILLIG, C. 2001. Introducing qualitative research in Psychology: Adventures in theory and method. Buckingham: Open University Press.

WILSON, H.V. 2001. Power and partnership: A critical analysis of the surveillance discourses of child health nurses. Journal of Advanced Nursing, 36(2):294-301.

WINSTANLEY, S. \& RICHARD, W. 2002. Anxiety, burnout and coping styles in general hospital staff exposed to workplace aggression: a clinical model of burnout and vulnerability to aggression. Work \& Stress, 16(4):302-315.

Mr Johannes Christiaan Schoombee, Mrs Johanna Marié van der Merwe and Professor Lou-Marie Kruger, Department of Psychology, University of Stellenbosch, Stellenbosch, South Africa. 